\title{
Retratos da Juventude: um Enfoque Sobre o Sistema Penitenciário do Estado do Rio Grande do Sul
}

\author{
Youth Pictures: A Focus on The Rio Grande do Sul State Penitentiary System
}

\author{
Manoel do Nascimento Filho*a; Suzana Schneider ${ }^{a}$
}

a Universidade de Cruz Alta. RS, Brasil.

*E-mail: manoel.nascimento773@gmail.com

\begin{abstract}
Resumo
O número de jovens do sexo masculino no sistema penitenciário é muito significativo. Entender em que situações se encontram os jovens infratores, no sistema penitenciário, provou ser um grande desafio. Este documento supera esses desafios visando relatar o contexto do sistema prisional, oferecendo novos insights sobre a realidade do encarceramento. O objetivo deste estudo é identificar os anseios e perspectivas dos jovens do sexo masculino, junto ao sistema prisional no Estado do Rio Grande do Sul, sob o olhar de profissionais que atum na área. Trata-se de uma pesquisa qualitativa, realizada entre os anos de 2011 a 2018. Os resultados apontam a falta de ressocialização dos detentos, um histórico de violência, a presença do tráfego de drogas no interior dos presídios, abusos e, o descontrole existente por parte do Estado.
\end{abstract}

Palavras-chave: Descontrole por Parte do Estado. Reincidência. Sistema Penitenciário.

\begin{abstract}
The number of young men in the prison system is very significant. Understanding the situation of young offenders in the prison system proved to be a great challenge. This document overcomes these challenges, aiming to report the prison system context by offering new insights into the reality of incarceration. The objective of this study is to identify the young men's desires and perspectives, with the prison system in the State of Rio Grande do Sul, under the eyes of professionals who work in the area. It is a qualitative research, carried out between the years 2011 to 2018. The results point to the lack of the detainees' re-socialization, a history of violence, the presence of drug traffic inside the prisons, abuses and, the existing lack of control by part of the state.
\end{abstract}

Keywords: State's Lack of Control. Recurrence. Penitentiary System.

\section{Introdução}

O sistema carcerário cria nas estruturas do direito uma expectativa de minimizar processos de criminalidade na quase totalidade dos países (PETER FILHO, 2011). A prisão tem como fundamentação filosófica a confinação como sendo a aprendizagem do isolamento, na qual ocorre a segregação da família, dos amigos e de outras relações socialmente significativas (BITENCOURT, 1993; FROIS, 2016). A pena, para Canterji (2008), atua como forma preventiva de crimes.

Para Foucault (1999, p.195): “a forma-prisão preexiste à sua utilização sistemática nas leis penais. Este é o sistema vigente no Brasil, todavia é preciso esclarecer que não é este o sistema ideal do ponto de vista da Constituição Brasileira."

"A violência está apontada como o mais recente fenômeno que permeia novas relações econômicas e políticas na vida dos jovens, como foco de nova estruturação social, prova disso são as políticas voltadas aos anseios e atendimento das demandas dos jovens, nas áreas de educação formal e qualificação de mão de obra, estimulada ao máximo pelos governos" (DRUKER, 1999, p. 201).

O total de pessoas encarceradas, no Brasil, tomando por base o Levantamento Nacional de Informações PenitenciáriasINFOPEN do Ministério da Justiça, chegou a 748.009 no ano de 2019, distribuídos da seguinte forma: 362.547 fechados, aberto 25.137, em tratamento ambulatorial 250, semiaberto 133.408, provisório 222.558 e em medida de segurança 4.109.

No Sistema Penitenciário do Rio Grande do Sul, especificamente, de acordo com o Departamento Penitenciário Nacional-DEPEN, ligado ao Ministério da Justiça e Segurança Pública referente ao mês de maio de 2020, apresentou um total de 38.858 , sendo 37.005 de homens e 1.853 de mulheres. O mesmo departamento apregoava, no período de julho a dezembro de 2019 , ter um total de 41.189 , desses números de presos 39.110 (94,95\%) são de homens e 2.079 de mulheres $(5,05 \%)$. Ainda, sobre a mesma base de dados, a faixa etária da população prisional masculina, em 2019, apresentou (19,16\%) na faixa entre $18-24$ anos, (19,45\%) entre 25 a 29 anos, (18,325\%) entre 30 a 34 anos, $(24,44 \%)$ entre 35 a 45 anos; (8,85\%) entre 46 a 60 anos e (1,46\%) entre 61 a 70 anos, $(0,36 \%)$ com mais de 70 anos e, $(2,92 \%)$ não informado.

Como instituições normativas se tem o Estado e todo o conjunto que permeia suas relações, dessa forma, os jovens dentro do sistema prisional e as instituições normativas se cruzam. Dessa forma, surgiram as seguintes questões de pesquisa: compreender o processo de aprisionamento, como esse ocorre de forma física e como acontece o evento "prender 
para reeducar, prender para punir ou prender para reinserção social?"

O presente trabalho tem por objetivo identificar os anseios e perspectivas dos jovens, do sexo masculino, sob olhar de profissionais atuantes na área, sobre o sistema penitenciário no Estado do Rio Grande do Sul.

Sendo assim, é justificável pesquisar porque alguns jovens, que pela ordem normativa, deveriam estar dentro das Universidades ou em uma vida mais regrada, ou ainda em busca da qualidade de vida com crescimento autônomo, em suas duas esferas, tanto afetivo quanto intelectual estão dentro do sistema prisional e quais seus anseios e perspectivas.

\section{Material e Métodos}

Este trabalho relata a experiência de profissionais, de setores públicos e privados sobre o assunto. $\mathrm{O}$ roteiro e o planejamento da pesquisa seguiram a abordagem proposta por Ribeiro; Milan (2007). Possui um caráter qualitativo, de cunho exploratório utilizando a pesquisa de campo, através da aplicação de entrevistas individuais, com roteiro semiestruturado, como técnica de coleta de dados.

No total foram aplicadas 10 entrevistas. Todas as entrevistas foram gravadas, visando se obter uma melhor compreensão e aproveitamento possível dos relatos dos entrevistados, sendo também efetuadas anotações de aspectos relevantes. Logo após o término de cada entrevista, essas entrevistas foram transcritas e as anotações foram ampliadas para um texto coerente. As pesquisas foram efetuadas entre os anos de 2011 a 2017, sendo as mesmas transcritas tão logo foram obtidas as respostas, de modo a facilitar a análise e a interpretação dos dados. Cabe salientar que os entrevistados foram escolhidos por conveniência, ou seja, de acordo com o acesso disponibilizado, conhecimento e experiência apresentada em relação à temática em estudo.

A descrição dos dados, neste trabalho, seguiu a ordem do entrevistador, ou seja, a ordem em que os fatos apareceram nas entrevistas, procurando-se seguir o roteiro como base de organização, com possibilidade de perguntas adicionais, quando do entendimento que essas perguntas pudessem ajudar a elucidar as questões básicas da pesquisa.

Para a interpretação se optou pelo apoio na teoria que serviu de suporte para a verificação dos relatos efetuados pelos entrevistados acerca dos relatos que estavam aparecendo, conforme a literatura consultada aponta, inclusive, encontrando-se algumas lacunas ainda a serem exploradas (RIBEIRO; NODARI, 2009). O Quadro 1 apresenta a caracterização dos participantes das entrevistas.
Quadro 1 - Perfil dos participantes das entrevistas

\begin{tabular}{|c|c|}
\hline Entrevistados & Perfil \\
\hline 1 & $\begin{array}{l}\text { Mulher, defensora pública atuando no } \\
\text { Estado do Rio Grande do Sul - RS, } \\
\text { advogada, } 56 \text { anos, com mais de } 25 \text { anos de } \\
\text { experiência. }\end{array}$ \\
\hline 2 & $\begin{array}{l}\text { Mulher, representante da secretaria nacional } \\
\text { dos direitos humanos/RS, tem } 49 \text { anos, } \\
\text { advogada e psicóloga. Possui } 20 \text { anos de } \\
\text { experiência sobre o assunto. }\end{array}$ \\
\hline 3 & $\begin{array}{l}\text { Homem, atua como inspetor de polícia civil/ } \\
\text { RS, } 51 \text { anos, advogado, } 12 \text { anos atuando na } \\
\text { área. }\end{array}$ \\
\hline 4 & $\begin{array}{l}\text { Homem, advogado do instituto de acesso da } \\
\text { justiça do Brasil, tem } 47 \text { anos, experiência } \\
\text { de } 25 \text { anos. }\end{array}$ \\
\hline 5 & $\begin{array}{l}\text { Homem, promotor público/RS, é advogado, } \\
\text { atuando há } 10 \text { anos como promotor. }\end{array}$ \\
\hline 6 & $\begin{array}{l}\text { Homem, inspetor da polícia civil/RS - } \\
\text { Advogado, } 49 \text { anos. Experiência de mais de } \\
15 \text { anos, sendo também pesquisador sobre } \\
\text { o assunto. }\end{array}$ \\
\hline 7 & $\begin{array}{l}\text { Mulher, atua como professora em uma } \\
\text { Universidade privada/RS. } \\
\text { Doutora em direito, Antropóloga, } 51 \text { anos, } \\
27 \text { anos de experiência. }\end{array}$ \\
\hline 8 & $\begin{array}{l}\text { Homem, professor federal atuando no } \\
\text { RS. Doutor em direito, mestre em serviço } \\
\text { social, advogado, } 43 \text { anos, com experiência } \\
\text { na advocacia e na docência por } 13 \text { anos. }\end{array}$ \\
\hline 9 & $\begin{array}{l}\text { Homem, servidor da brigada militar e } \\
\text { atuante em diversos projetos em Direitos } \\
\text { Humanos no Estado do Rio Grande do Sul, } \\
54 \text { anos com experiência de } 30 \text { anos. }\end{array}$ \\
\hline 10 & $\begin{array}{l}\text { Mulher, diretora em uma ONG/RS, } \\
\text { especializada na atuação de direitos } \\
\text { humanos ligados ao sistema penitenciário, } \\
\text { atuando em diversos Estados brasileiros } \\
\text { ligados às esferas estaduais e municipais. } \\
\text { Instrutora e capacitadora de cursos na } \\
\text { área. Tem } 42 \text { anos, socióloga, doutora em } \\
\text { sociologia. }\end{array}$ \\
\hline
\end{tabular}

Fonte: Dados da pesquisa.

\section{Resultados e Discussão}

As entrevistas realizadas tiveram o propósito de captar a percepção e explorar a experiência. Por fins didáticos serão apresentados os resultados, sempre apontando evidências da literatura, que confirmem ou não as opiniões destes.

A partir das questões centrais do roteiro semiestruturado (Quadro 2), a análise foi dividida levando em consideração os questionamentos efetuados. Foi utilizada para organização dos dados coletados a metodologia da Análise de Conteúdo proposta por Bardin (2011). Alguns aspectos individuais foram relatados no desenvolvimento das questões e evidenciados também pela literatura. Salienta-se, entretanto, que nem todos os fatores encontrados nas pesquisas encontram sustentação na literatura. 
Quadro 2 - Roteiro das questões semiestruturado

Prezado entrevistado, estamos estudando os anseios e perspectivas dos jovens dentro do sistema penitenciário, sob o olhar de profissionais que atuam na área. Será guardado sigilo sobre sua identidade.

Idade:

Escolaridade:

Qual sua experiência sobre o tema?

Quanto tempo trabalha com este tema/atua na área?

Onde trabalha atualmente e onde mais já trabalhou com este assunto?

\begin{tabular}{|l|c|}
\hline \multicolumn{1}{|c|}{ Questões } & Suporte de Autores \\
\hline Q1. Qual a posição dos jovens dentro do sistema prisional e em relação à violência? & Laranjeira, 2007. \\
\hline $\begin{array}{l}\text { Q2. Ao sair da vida em comunidade e ir para o espaço de reclusão, se pressupõem que é } \\
\text { por determinado tempo. Esse tempo que a pessoa fica presa, na realidade de hoje, de que } \\
\text { maneira ela é devolvida para a sociedade? }\end{array}$ & Barbosa, 2012; Marcão, 2005. \\
\hline $\begin{array}{l}\text { Q3. Quando um jovem entra no sistema prisional e vai ficar certo período de tempo, } \\
\text { percebe-se a evolução, pela via negativa? }\end{array}$ & $\begin{array}{c}\text { Assis, 2007; Oliveira, 2001; Machado; } \\
\text { Guimarães, 2014. }\end{array}$ \\
\hline Q4. "E dentro do presídio, sobre a questão do tráfico de drogas?" & Correia 2010. \\
\hline $\begin{array}{l}\text { Q5. Onde você acha que está a raiz de toda problemática que se vive? como isso deságua } \\
\text { na segurança pública? }\end{array}$ & Araújo, 2012. \\
\hline $\begin{array}{l}\text { Q6. Tem uma expressão assim: tu passas a ser lixo, é uma expressão deles. É porque se } \\
\text { consideram lixo que não ocorre o processo de ressocialização? }\end{array}$ & Fernandez; Boczar, 2011; Martins; \\
\hline $\begin{array}{l}\text { Q7. Ao ingressar no sistema prisional o jovem é um aprendiz. Nesse processo de } \\
\text { aprendizado pela via negativa, ele tem chance de crescer dentro da organização ou } \\
\text { dentro das galerias ou facção que ora vai estar inserido. }\end{array}$ & \begin{tabular}{c} 
Busso; Jesse; Kline, 2013; Jeffrey, 1995. \\
\hline Q8. Existe opções para mudança nesse sistema existente?
\end{tabular} \\
\hline
\end{tabular}

Fonte: Dados da pesquisa.

As entrevistas foram realizadas de forma individual, através de cronograma preestabelecido, em que os entrevistados iam respondendo. A partir das entrevistas, que foram realizadas, através de gravação para posterior transcrição e digitação das respostas coletadas (BOURDIEU, 1999).

Em posse desses materiais coletados foi possível a construção de alguns fatores considerados importantes nas entrevistas realizadas, expostas a seguir:

Q1- Qual a posição dos jovens dentro do sistema prisional e em relação à violência?, foram apontados 8 fatores pelos participantes, que são: pobres, marginalizados, invisíveis socialmente, Estado não reabilita, reincidência, crime como modo de vida, insegurança, histórico de abusos e negligências.

[...] muitos jovens são mortos em função da violência. Eles têm de se adaptar, ou melhor, sobreviver (Entrevista 1).

[...] são reincidentes, sem escolaridade, de família desestruturada com convívio diário de violência e abusos de toda forma (Entrevista 8).

[...] quem morre são os mais pobres, são os marginalizados, são aqueles que também são invisíveis socialmente (Entrevista 2, 7).

Os autores, que dão sustentação a esses fatores, abordam que o inserido dentro do sistema prisional, em sua grande maioria, é de jovens que anteriormente já vêm com um histórico de delinquência (AIZER; DOYLE, 2015; LARANJEIRA, 2007). Para Penteado Filho (2013), eles são oriundos de processos urbanos de violência, sendo que nesse meio os Direitos Humanos são separados da segurança pública, garantidora de Saúde, Educação e acessos a determinantes de qualidade de vida (BERNARDES, 2015).

Q2- Ao sair da vida em comunidade e ir para o espaço de reclusão, se pressupõem que é por determinado tempo. Esse tempo que a pessoa fica presa, na realidade de hoje, de que maneira ela é devolvida para a sociedade? Nas entrevistas foram identificados 3 fatores: inexistência de ressocialização, existência de espaço no sistema penitenciário marcado pela violência constante e direitos violados além da liberdade e, superpopulação.

[...] atualmente, o sistema que temos devolve muito pior do que quando entrou, porque o espaço hoje da prisão é um espaço de violência e violação constante (Entrevista 6).

[...] quando a pessoa entra lá dentro só tem, na verdade, direitos violados, muito além da sua liberdade cerceada (Entrevista 5).

[...] a superlotação é uma realidade (Entrevista 3).

Entende-se a prática da ressocialização, conforme Marcão (2005) e o Conselho Nacional de Justiça (2012), como uma necessidade de promover ao apenado, condições de reestruturação, a fim de que ao voltar à sociedade, não mais torne a delinquir. Entretanto, a pena privativa de liberdade, conforme Veloso (2016), não ressocializa, ao contrário, estigmatiza o recluso, impedindo sua plena reincorporação ao meio social. A prisão não cumpre a sua função ressocializadora (HATZENBUEHLER et. al.,2015). Serve como instrumento para a manutenção da estrutura social de dominação (ASSIS; ÂNGELO; WERMUTH, 2015).

Cavalcante (2010) ressalta a existência de superlotação dentro dos presídios, o que caracteriza mais violência, em que detentos de alta periculosidade cumprem pena com outros que ainda são primários. O próprio sistema, de acordo com Alves (2012), gera um ambiente propício para um comportamento ainda mais violento por parte do indivíduo. Depois de um tempo encarcerado, o indivíduo acaba sendo devolvido à sociedade pior do que quando entrou no sistema penitenciário, assim, o atual sistema frustram os fins aos quais foram criados (ANDRADE; FERREIRA, 2015; DA 


\section{CUNHA, 2010).}

Q3- Quando um jovem entra no sistema prisional e vai ficar certo período de tempo, percebe-se a evolução, pela via negativa? Nessa questão foram identificados 5 fatores: amargura, reincidência, sentimento de pertencimento ao crime, falta de opção e estarem à margem da sociedade.

[...] a entrada no sistema prisional, na linguagem popular ele vai fazer um pós-graduação. Ele vai conhecer novos indivíduos autores de crimes danosos ao meio social, vai ficar com estigma do sistema prisional, em geral, quando sai não tem estrutura familiar nem intelectual para entrar no mercado de trabalho. A tendência dele é voltar a reincidir na delinquência e retornar ao sistema prisional (Entrevista 6).

[...] atualmente, o sistema que temos devolve muito pior do que quando entrou, porque o espaço hoje da prisão é um espaço de violência e violação constante (Entrevista 9).

[...] 400 presos ter de dividir sete rolos de papel higiênico durante um período de uma semana é a coisa mais absurda que tem (Entrevista 4).

[...] Não existe mais opções, restou a criminalidade (Entrevista $1)$.

O sistema prisional brasileiro tem como objetivo a ressocialização e a punição da criminalidade (FOUCALT, 2011). Sobre a prisão, como forma de aplicação de medida ressocializadora, o mesmo autor (1994, p. 236) afirmou que "a prisão não pode deixar de fabricar delinquentes. Fabrica-os pelo tipo de existência que faz os detentos levarem: o isolamento nas celas ou superlotação, imposição de um trabalho inútil, e total descontrole". O tempo ocioso produz no jovem uma sensação de inutilidade e o estimula à experiência de investimento absoluto no presente, resultando em um período de "estadia" vazio, sem novas aprendizagens, que lhe procrastina ainda mais a necessária ressocialização (HURREN; STEWART; DENNISON, 2017; OLIVEIRA, 2001).

Tanto para Assis (2007), como para Machado e Guimarães (2014), a desestruturação do sistema prisional ocasiona o descrédito da prevenção e da reabilitação do condenado, ante um ambiente, cujo fatores culminaram para que chegasse a um precário sistema prisional.

Q4- "E dentro do presídio, sobre a questão do tráfico de drogas?" 5 fatores foram relatados: meio de sobrevivência, existência de quadrilhas, exploração pelo dinheiro, tortura no sistema penitenciário e realidade que não se reconhece.

[...] não é só isso. Vamos levar para outro exemplo. Alguém que chega num presídio sempre tem o dono da galeria e existe um grupo de pessoas que são chamadas de prefeitura. A prefeitura é que comanda, então é muito rentável para eles a forma que eles trabalham, não é somente com drogas (Entrevista 5).

[...] para chegarem a determinados benefícios, os presos têm de pagar pedágio para a prefeitura. Tudo tem de pagar, tudo gera dinheiro (Entrevista 6).

[...] se alguém usa droga dentro da cadeia e fica devendo, vai ter de pagar talvez até com a sua própria vida (Entrevista 6).

[...] a família é obrigada a trazer dinheiro, mas tem família que não tem, e aí? (Entrevistas 3 e 9).

O uso de drogas e também o tráfico ilegal no Sistema Penitenciário está diretamente relacionado a mortes e crimes, em geral, o questionamento é como este fato é permitido? Não cabe ao Estado inibir e controlar? (LERMEN; DARTORA; RAMOS, 2014). Os pesquisadores Stockings, Hall e Lynskey (2016) relatam que entorpecentes são detidos com frequência dentro dos presídios e nas penitenciárias, nesse sentido, se constata a omissão do Estado em se fazer cumprir as regras que os condenados pela Justiça deveriam seguir dentro dos Presídios.

Q5- Onde você acha que está a raiz de toda problemática que se vive? como isso deságua na segurança pública? Nessa questão, foram evidenciados 11 fatores: incapacidade da segurança pública em manter a ordem e aplicar a lei com rigor sem desrespeitar os direitos humanos dos apenados, Estado a serviço de uma minoria, segurança pública que não consegue inibir as atividades do crime organizado; falta de valores humanos; tortura e maus-tratos; falta de justiça; fracasso das políticas públicas; falta de empreendimentos de geração de renda; fruto do meio, perdas psicológicas e tráfico como meio de sobrevivência.

[...] o Estado brasileiro serve a uma minoria, que serve a tipologia em relação à situação da pessoa de renda, seja de cor de pele, seja em relação à orientação sexual, seja em relação à pobreza, sem pertencimento (Entrevistas 7 e10).

[...] quando o próprio Estado não dá segurança aos presos, permite gestão paralela dentro dos presídios, com poder ilimitada para facções de criminosos (Entrevista 9).

[...] existência de abusos, superlotação, miséria e insegurança jurídica e de proteção (Entrevista 4).

Baggio et al. (2018) descrevem que os prisioneiros não só são submetidos a tratamentos brutais frequentes, como convivem em condições de miséria e de superlotação, sendo que em muitas cadeias - senão a quase totalidade dessas - são administradas por determinados grupos ou facções (CORREIA, 2010).

Já como violador do sistema se encontra o próprio sistema que deixa claro o entendimento do Estado como principal instrumento da violação institucional (JENNINGS et al., 2017). Araújo (2012) e Brasil (2015) relatam que, tanto quanto for possível, incumbe ao Estado adotar medidas preparatórias ao retorno do condenado ao convívio social.

Q6- Tem uma expressão assim: tu passas a ser lixo, é uma expressão deles. E porque se consideram lixo que não ocorre o processo de ressocialização? Destacou 4 fatores: a baixa autoestima, o sentimento de perda, a questão da exclusão e o abandono familiar e do Estado.

[...] na verdade são exatamente isso, treze pessoas num cubículo, como a pessoa vai sair dali ressocialização. Impossível no atual sistema (Entrevista 1).

[...] é outro jeito de viver muito complicado que te arremete a ser lixo (Entrevista 4).

[...] temos a ideia de que quanto mais organizada a sociedade, menos crime haverá. A sociedade compactua, com a mendicância, quando é criança, quando é jovem não compactua mais, daí eles começam a roubar, fazem coisas pra manter aquele padrão (Entrevista 5).

O perfil psicológico e comportamental dos jovens perpassa por fatores como manipulação, a inconsequência natural dos jovens, o imediatismo, principalmente, de bens materiais, falsa ideia da impunidade, dessa forma, independentemente de estarem ou não encarcerados, o princípio é o mesmo, o que altera é a situação momentânea de cada um (MARTINS; 
OLIVEIRA, 2013). Nesse sentido, a ressocialização deve ser buscada como forma do resgate da dignidade humana, da recuperação da autoestima do detento, aconselhamento e condições de melhorias pessoais com projetos ligados a anseios profissionais, entre outras formas de incentivo (FERNANDEZ; BOCZAR, 2011).

Q7- Ao ingressar no sistema prisional o jovem é um aprendiz. Nesse processo de aprendizado pela via negativa, ele tem chance de crescer dentro da organização ou dentro das galerias ou facção que ora vai estar inserido. Existe uma maneira de haver uma ruptura nesse processo, baseado no seu conhecimento de vida em sociedade? Dois fatores foram evidenciados nessa questão: a exclusão da sociedade que leva ao engajamento do crime (pela arma e droga) e existência de pedágios:

[...] o sistema prisional não é um sistema feito como Programa de Política Pública para recuperação do apenado ou mesmo do detido, ao contrário, é uma política e uma prática que o excluí da sociedade (Entrevista 10).

[...] quando se exclui da sociedade, das alternativas da vida legal da sociedade, oferece em contrapartida uma outra forma de engajamento na economia, que é exatamente a economia do crime, de um tipo de crime vinculado a arma e a droga (Entrevista 6).

Além da discriminação e preconceito, a partir do egresso, no sistema penitenciário, os jovens apenados encontram como barreiras: habilidades e potencialidades laborais fracas, falta de conexões e experiências recentes de trabalho, de educação limitada, de histórico de uso/abuso de substâncias ilícitas e outros problemas de ordem física e mental (BUSSO; JESSE; KLINE, 2013; RAJ et al., 2014.). Como a prisão não reintegra, o egresso sai do presídio sem condições mínimas de sobrevivência, tais como: habitação, saúde, família, trabalho, enfim, conviver em sociedade, o que os lança diretamente na reincidência (WILLIAN et al., 2014).

Para muitos ao regressar à sociedade, a única opção é encontrar oportunidade no trabalho autônomo, ou lamentavelmente, buscar na criminalidade uma opção de obtenção de renda, dessa forma, ao sair tem mínimas chances de mudar de vida (CHERRIE; BARBER, 2016; GOMIDE,
1988).

Q8- Existe opções para mudança nesse sistema existente? Foram destacados 13 fatores, sendo esses: Estado como garantidor de ressocialização, capacitação profissional, convivência familiar, garantia à vida, celas com segurança, escola como direito, separação dos presos por especialidade dos delitos, visita como direito, redução de pena por trabalho, tutela do Estado, combate ao tráfico, criação de um novo modelo de presídio e direito à saúde.

[...] o Estado deve realmente garantir a ressocialização (Entrevista 2).

[...] As celas deveriam dar segurança (Entrevista 4).

[...] separar os presos por especialidade dos delitos, dar condições dignas de alimentação, leito e saúde (Entrevista 7).

[...] o jovem tem de entrar no sistema e sair de lá pronto para dar conta de todas as contradições sociais e a sociedade tem de receber esse jovem, ou pelo menos deveria (Entrevistas $5,7$ e 8$)$.

A crítica situação do sistema prisional brasileiro pode ser explicada por diversos fatores, um desses é o alto número de "ex-apenados" que retornam ao sistema penal e, por consequência, acarretam em uma superlotação das prisões (LOEFLER, 2013; SAPORI et al., 2017). Outro aspecto é entender as causas da reincidência criminal e de que formas essas podem ser combatidas (PHILIP; KANG, 2016; STAGGS; LANDREVILLE, 2017).

$O$ fato de os infratores não passarem por uma verdadeira reeducação, enquanto encarcerados, faz com que estes, ao saírem, voltem a delinquir, fato comprovado pelos altos índices de reincidência, interferindo, assim, diretamente na questão da violência urbana e contribuindo para essa sensação de insegurança tão presente nestes dias (Bessil et al., 2017; VISHER et al., 2017). Uma alternativa é que Governos apoiem uma abordagem de prevenção ao crime, fazendo cumprir as penas de restrição de liberdade com observância de garantias individuas (OLIVEIRA, 2012; SINHORETTO, 2014).

Para melhor compreensão da temática, de uma forma mais resumida, a seguir foram identificados os fatores apontados nas entrevistas e os autores que deram sustentabilidade as entrevistas (Quadro 3).

Quadro 3 - Fatores apontados nas entrevistas e os autores que reforçam as entrevistas

\begin{tabular}{|c|c|c|}
\hline Questões do Roteiro Semiestruturado & Fatores Apontados nas Entrevistas & Autores que Reforçam as Entrevistas \\
\hline $\begin{array}{l}\text { Q1. Qual a posição dos jovens dentro } \\
\text { do sistema prisional e em relação à } \\
\text { violência? }\end{array}$ & $\begin{array}{l}\text { - Jovens assassinados } \\
\text { - Pobres } \\
\text { - Marginalizados } \\
\text { - Invisíveis socialmente } \\
\text { - Estado não reabilita } \\
\text { - Reincidência } \\
\text { - Crime como modo de vida } \\
\text { - Manipuladores } \\
\text { - Insegurança } \\
\text { - Miséria } \\
\text { - Histórico de abusos e negligências }\end{array}$ & Laranjeira, 2007. \\
\hline $\begin{array}{l}\text { Q2. Ao sair da vida em comunidade e ir } \\
\text { para o espaço de reclusão, se pressupõem } \\
\text { que é por determinado tempo. Esse } \\
\text { tempo que a pessoa fica presa, na } \\
\text { realidade de hoje, de que maneira ela é } \\
\text { devolvida para a sociedade? }\end{array}$ & $\begin{array}{l}\text { - Inexistência de ressocialização } \\
\text { - Existência de espaço no sistema } \\
\text { penitenciário marcado pela violência } \\
\text { constante } \\
\text { - Direitos violados além da liberdade } \\
\text { - Superpopulação }\end{array}$ & $\begin{array}{l}\text { Alves, 2012; Andrade; Ferreira, 2015; } \\
\text { Assis, Ângelo; Wermuth, 2015; Barbosa, } \\
\text { 2012; Cavalcante, 2010; Da Cunha, } \\
\text { 2010; Hatzenbuehler, 2015; Stürup et } \\
\text { al., 2018. }\end{array}$ \\
\hline
\end{tabular}




\begin{tabular}{|c|c|c|}
\hline Questões do Roteiro Semiestruturado & Fatores Apontados nas Entrevistas & Autores que Reforçam as Entrevistas \\
\hline $\begin{array}{l}\text { Q3. Ao sair da vida em comunidade e ir } \\
\text { para o espaço de reclusão, se pressupõem } \\
\text { que é por determinado tempo. Esse } \\
\text { tempo que a pessoa fica presa, na } \\
\text { realidade de hoje, de que maneira ela é } \\
\text { devolvida para a sociedade? }\end{array}$ & $\begin{array}{l}\text { - Amargurado } \\
\text { - Reincidente } \\
\text { - Sentimento de pertencimento ao crime } \\
\text { - Falta de opção } \\
\text { - À margem da sociedade } \\
\end{array}$ & $\begin{array}{l}\text { Hurren; Stewart; Dennison, 2017; } \\
\text { Oliveira, 2001. }\end{array}$ \\
\hline $\begin{array}{l}\text { Q4. E dentro do presídio, sobre a questão } \\
\text { do tráfico de drogas? }\end{array}$ & $\begin{array}{l}\text { - Meio de sobrevivência } \\
\text { - Existência de quadrilhas } \\
\text { - Exploração pelo dinheiro } \\
\text { - Tortura no sistema penitenciário } \\
\text { - Realidade que não se reconhece }\end{array}$ & $\begin{array}{l}\text { Lermen; Dartora; Ramos, 2014; } \\
\text { Stockings; Hall; Lynskey, 2016. }\end{array}$ \\
\hline $\begin{array}{l}\text { Q5. Onde você acha que está à raiz de } \\
\text { toda problemática que se vive? como } \\
\text { isso deságua na segurança pública? }\end{array}$ & $\begin{array}{l}\text { - Incapacidade da Segurança Pública em } \\
\text { manter a ordem e aplicar a lei com rigor } \\
\text { sem desrespeitar os Direitos Humanos dos } \\
\text { apenados } \\
\text { - Estado a serviço de uma minoria } \\
\text { - Segurança Pública não consegue inibir as } \\
\text { atividades do crime organizado } \\
\text { - Falta de valores humanos } \\
\text { - Tortura e maus-tratos } \\
\text { - Falta de justiça } \\
\text { - Fracasso das políticas públicas } \\
\text { - Falta de empreendimentos de geração de } \\
\text { renda } \\
\text { - Fruto do meio } \\
\text { - Perdas psicológicas } \\
\text { - Tráfico como meio de sobrevivência } \\
\text { - Falta de programa de política pública para } \\
\text { recuperação }\end{array}$ & $\begin{array}{l}\text { Baggio et al., 2018; Bernandes, 2015; } \\
\text { Jennings et al., 2017; Mallart, 2014; } \\
\text { Mcleigh; Sianko, 2010. }\end{array}$ \\
\hline $\begin{array}{l}\text { Q6.Tem uma expressão assim: tu passas } \\
\text { a ser lixo, é uma expressão deles. É } \\
\text { porque se consideram lixo que não } \\
\text { ocorre o processo de ressocialização? }\end{array}$ & $\begin{array}{l}\text { - Baixa autoestima } \\
\text { - Sentimento de perda } \\
\text { - Exclusão } \\
\text { - Abandono familiar e do Estado } \\
\end{array}$ & $\begin{array}{l}\text { Fernandez; Boczar, 2011; Martins; } \\
\text { Oliveira, 2013. }\end{array}$ \\
\hline $\begin{array}{l}\text { Q7. Ao ingressar no sistema prisional o } \\
\text { jovem é um aprendiz. Nesse processo de } \\
\text { aprendizado pela via negativa, ele tem } \\
\text { chance de crescer dentro da organização } \\
\text { ou dentro das galerias ou facção que ora } \\
\text { vai estar inserido. }\end{array}$ & $\begin{array}{l}\text { - Exclusão da sociedade que leva ao } \\
\text { engajamento do crime (pela arma e droga) } \\
\text { - Existência de pedágio }\end{array}$ & $\begin{array}{l}\text { Busso; Jesse; Kline, 2013; Cherrie; } \\
\text { Barber, 2016; Raj et al., 2014; Steven, } \\
\text { 2011. }\end{array}$ \\
\hline $\begin{array}{l}\text { Q8.Existe opções para mudança nesse } \\
\text { sistema existente? }\end{array}$ & $\begin{array}{l}\text { - Estado como garantidor de ressocialização } \\
\text { - Capacitação profissional } \\
\text { - Convivência familiar } \\
\text { - Garantia à vida } \\
\text { - Celas com segurança } \\
\text { - Escola como direito } \\
\text { - Separação dos presos por especialidade dos } \\
\text { - delitos } \\
\text { - Visita como direito } \\
\text { - Redução de pena por trabalho } \\
\text { - Tutela do Estado } \\
\text { - Combate ao tráfico } \\
\text { - Criação de um novo modelo de presídio } \\
\text { - Direito à saúde }\end{array}$ & $\begin{array}{l}\text { Bessil et al., 2017; Ebel et al., 2011; } \\
\text { Loefler, 2013; Oliveira, 2012; Philip; } \\
\text { Kang, 2016; Sapori et al., 2017; Staggs; } \\
\text { Landreville, 2017; Veloso, 2016; Visher } \\
\text { et al., 2017. }\end{array}$ \\
\hline
\end{tabular}

Fonte: Dados da pesquisa.

\section{Conclusão}

O presente estudo procurou chamar a atenção para a possibilidade de interface entre os setores que compõem a complexidade das Instituições, enquanto moderadoras de comportamento. A busca por resposta urge que ocorra envolvimento. Dessa maneira, ao referenciar teoricamente e buscar pessoas com conhecimento sobre o assunto se revelou ser de grande valia, pois sem as informações de alta relevância prestadas pelos entrevistados não seria possível o desvelo e entendimento do que seria o sistema prisional estabelecido.

As instituições normativas estão à mercê da burocracia e legalidade, ao tempo que valores e conceitos filosóficos, pedagógicos e sociológicos são substituídos pela ineficiência de um conjunto de soluções cotidianas e usando da segurança pública como o grande culpado da ineficiência.

Os direitos humanos procuram garantir o cumprimento da lei para todos, em uma cruzada injusta na tentativa de assegurar direitos básicos do ser humano. Tanto que 
os "direitos humanos" não são reconhecidos pela grande maioria da população com seu caráter de humanidade e não considera a possibilidade dos seus direitos. A invisibilidade e o desrespeito a estes segmentos contribuem para a construção de medo e da intolerância.

Os direitos humanos procuram garantir o cumprimento da lei para todos, em uma cruzada injusta na tentativa de assegurar direitos básicos do ser humano. Tanto que os "direitos humanos" não são reconhecidos pela grande maioria da população com seu caráter de humanidade e não considera a possibilidade dos seus direitos. A invisibilidade e o desrespeito a estes segmentos contribuem para a construção de medo e da intolerância. O indivíduo, ao ser condenado, perde completamente sua liberdade, mas não deixa de ser um ser humano, devendo ser tratado como tal, pois só assim será possível que, ao voltar para o convívio social, não volte a delinquir.

Como o tráfico de drogas continua sendo de enorme lucratividade, tanto para jovens ou para uma grande parte da população carcerária, os entrevistados, em sua grande maioria, afirmam que a redução da maioridade penal somente reforçaria o caótico sistema penal brasileiro, não resolvendo ou diminuindo o problema da criminalidade, para eles o mais precário de medidas socioeducativas é melhor que o sistema prisional vigente. Portanto, cabe ao Estado buscar novas alternativas para o problema da delinquência juvenil, pois o tempo atrás das grades pode e deve ser utilizado para lhe garantir oportunidades, por meio de estudo e, paralelamente, de trabalho profissionalizante.

Chega-se à conclusão, ante o exposto neste artigo, que seria essencial e necessária a construção de novas unidades prisionais, com objetivo de desafogar esse sistema reconhecido pela superlotação existente. É fundamental que ocorram mudanças extremas neste sistema, uma vez que os presídios se tornaram verdadeiras "fábricas de revolta humana".

A realidade dos presídios hoje é a falta de manutenção das cadeias públicas, consumo e comercialização de drogas e o cumprimento de leis "próprias", que são estabelecidas pelas lideranças existentes entre os próprios presos.

A realidade do sistema prisional brasileiro no tratamento dos presos é totalmente indigno, quando a realidade deveria ser a ocorrência do devido cumprimento legal.

\section{Referências}

AIZER A.; DOYLE Jr. J. Juvenile incarceration, human capital, and future crime: Evidence from randomly assigned judges. Quarterly J. Econom., v.130, n.2, p.759-803, 2015.

ALVES, C. Reincidência Criminal: um olhar transdisciplinar. Porto Alegre: Conceito Editorial, 2012.

ANDRADE, U.; FERREIRA, F. Crise do Sistema Penitenciário Brasileiro: capitalismo, desigualdade e prisão. Rev. Psicol. Divers. Saúde, p.116-129, 2015.

ARAÚJO, E.D.P. Prisão e socialização: a penitenciária Lemos Brito. Rev. CEJ, n.36, p.87, 2007.
ASSIS, L.R.; ÂNGELO, M.; WERMUTH, D. A seletividade punitiva no contexto da biopolítica e a produção da vida nua (homo sacer) no sistema carcerário brasileiro: a relevância de políticas públicas comprometidas com a qualidade de vida e a dignidade humana do apenado. In: SEMINÁRIO INTERNACIONAL DEMANDAS SOCIAIS E POLÍTICAS públicas na sociedade contemporânea. Mostra internacional de trabalhos científicos. Santa Cruz do Sul: Unisc, 2015.

ASSIS, R.D. As prisões e o direito penitenciário no Brasil, 2007. Disponível em: https://www.direitonet.com.br/artigos/ exibir/3482/As-prisoes-e-o-direito-penitenciario-no-Brasil

BAGGIO, S. et al. Association of Overcrowding and Turnover with Self-harm in a swiss pre-trial prison. Int. J. Envirom. Res. Public Healt, v, 15, p.601, 2018.

BARDIN, L. Análise de conteúdo. São Paulo: Edições 70, 2011.

BESSIL, M.H.; MERLO, A.; CRESPO, R.. A prática docente de educação de jovens e adultos no sistema prisional. Psicol. Escolar Educac., v.21, n.2, p.285-293, 2017.

BOURDIEU, P. A miséria do mundo. Petrópolis: Vozes, 1999.

BRASIL. Estatuto da Criança e do Adolescente. Câmera dos Deputados, Lei no 8.069, de 13 de julho de 1990. DOU de 16/07/1990 - ECA. Brasília, DF.

BRASIL. Presidência da República. Secretaria Geral. Mapa do encarceramento: os jovens do Brasil. Brasília: Secretaria-Geral da Presidência da República e Secretaria Nacional, 2015.

BRASIL. Ministério da Justiça e Segurança Pública. Departamento Penitenciário Nacional - INFOPEN - Informações Penitenciárias. Brasília: Ministério da Justiça e Segurança Pública, 2019.

BRASIL. Departamento Penitenciária Nacional. Ministério da Justiça e Segurança Pública. Dados do Estado do Rio Grande do Sul. Disponível em $<$ http://depen.gov.br/DEPEN/depen. Acesso em: 20 mar. 2020.

BUSSO, M.; JESSE, G.; KLINE, P. Assessing the incidence and efficiency of a prominent place based policy. Am. Economic Rev., v.103, n.2, p.897-947, 2013.

CANTERJI, R.B. Política criminal e direitos humanos. Porto Alegre: Livraria do Advogado, 2008.

CARVALHO FILHO, L.F. A prisão. São Paulo: Publifolha, 2002.

CAVALCANTE, K.L. A problemática da ressocialização penal do egresso no atual sistema prisional brasileiro. Bol. Jurídico, n.581, 2010.

CHERRIE, B.; BARBER, A. The price we pay: economic costs of barriers to employment for former prisoners and people convicted of felonies. Washington: Center $\mathrm{f}$ or Economic and Policy Research, 2016.

CONSELHO NACIONAL DE JUSTIÇA. Panorama Nacional: A execução das medidas socioeducativas de Internação. Conselho Nacional de Justiça, 2012.

CORREIA, L.R. Sistema penitenciário brasileiro: falência nas prisões. São Bernardo do Campo: Universidade Metodista de São Paulo, 2010.

DA CUNHA, E. Ressocialização: o desafio na educação no sistema prisional feminino. Cad. Cedes, v.30, 2010.

DRUCKER, P. Administrando em tempos de grandes mudanças. São Paulo: Pioneira, 1999.

FACCHINI NETO, E. Premissas para uma análise da contribuição do juiz para efetivação dos direitos da criança e do adolescente. Rev. Juizado Infância Juventude, v.2, n.2, p.9, 2004.

FASSIN, D. Mundos da prisão: uma etnografia da condição 
carcerária. Cambridge: Polity Press, 2016.

FERNANDES, D.C.; BOCZAR, S. A ressocialização do sentenciado a luz da dignidade humana: programas e atividades no presídio de Alfenas. Âmbito

Jurídico, v.14, n.90, 2011.

PENTEADO FILHO, N.S. Manual esquemático de criminologia. São Paulo: Saraiva, 2013.

FROIS, C. The criminal act at the core of the nexus securityinsecurity: a tentative approach to female crime. In: GOMES, S; DUARTE, V. Female crime and delinquency in Portugal: in and out of the Criminal Justice System. London: Palgrave Macmillan, 2018. p.25-40.

FOUCAULT, M. Vigiar e punir: nascimento da prisão. Petrópolis: Vozes, 2011.

FOUCAULT, M. A verdade e as formas jurídicas. Rio de Janeiro: Nau, 1999.

GOMIDE, P.I.C. A instituição e a identidade do menor infrator. Psicol. Ciênc. Prof., v.8, n.1, p.20-22, 1988.

HATZENBUEHLER $M$. et al. The collateral damage of mass incarceration: Risk of psychiatric morbidity among nonincarcerated residents of high-incarceration neighborhoods. Am. J. Public Health, v.105, n.1, p.138-143, 2015.

HUGHES, N. et al. The prevalence of traumatic brain injury among young offenders in custody: a systematic review'. J. Head Trauma Rehab., v.30, n.2, p.94-105, 2015.

HURREN E.; STEWART A.; DENNISON S. Transitions and turning points revisited: a replication to explore child maltreatment and youth offending links within and across Australian cohorts. Child Abuse Neglect ., v.65, p.24-36, 2017.

JENNINGS W, et al. Penal populism and the public thermostat: crime, public punitiveness, and public policy. Governance, v.30, p.463-481, 2017.

KERR, A..; WILLIS, M. Prisoner use of information and communications technology. Trends Issues Crime Criminal Justice, v.50, p.8, 2018.

LARANJEIRA, C.A. A análise psicossocial do jovem delinquente: uma revisão da literatura. Psicol. Estud., v.12, n.2, p.221-227, 2007.

LERMEN, H.S.; DARTORA, T.; RAMOS, C.C. Drogadição no cárcere: questões acerca de um projeto de desintoxicação de drogas para pessoas privadas de liberdade. Studies Res. Psychol., v.14, n.2, 2014.

LOEFFLER, C.E. Does imprisonment alter the life course? Evidence on crime and employment from a natural experiment". Criminology, v,.1, n.51, p.137-166, 2013.

MALLART, F. Cadeias dominadas: a Fundação Casa, suas dinâmicas e a trajetória de jovens internos. São Paulo: Terceiro Nome, 2014.

MARCÃO, R. Curso de Execução Penal. São Paulo: Saraiva, 2005.

MARTINS, H.T.; OLIVEIRA, V.N. Crime, criminosos e prisão: um estudo sobre a reincidência penitenciária em Montes Claros MG. Rev. Bras. Segur. Pública, v.7, n.2, p.32-48, 2013.

O'DONNELL, I. Prison coping and adaptativo. In: BOSWORTH, M.; HOYLE, C.; ZEDNER, L. Changing contours in criminal justice. Oxford: Oxford University Press, 2016, p.169-181.
O’DONNELL, G. Contrapontos autoritarismo e democratização. São Paulo: Vértice, 1986.

OLIVEIRA, C.S. Sobrevivendo no inferno. Porto Alegre: Sulina, 2001.

OLIVEIRA, C. Notas Sobre a Justiça Restaurativa. Rev. Síntese, v.13, n.75, p.54-73, 2012.

OLIVEIRA, E. O futuro alternativo das prisões. Rio de Janeiro: Forense, 2002.

PETER FILHO, J. Reintegração social: um diálogo entre a sociedade e o cárcere. São Paulo: Universidade de São Paulo, 2011

PHILIP, C.J.; KANG, S. Birthdays, schooling, and crime: regression-discontinuity analysis of school performance, delinquency, dropout, and crime initiation. Am. Econom. J. Appl. Econom, v.8, n.1, p.33-57, 2016.

RAJ, C. et al. Where is the land of opportunity? The Geography of Intergenerational Mobility in the United States. Quarterl. J. Econom., v.129, n.4, p.1553-1623, 2014.

RELATÓRIO AZUL 2004. Garantias e violações dos direitos humanos: 10 anos. Porto Alegre: CORAG, 2004.

RIBEIRO, J.L.D.; MILAN, G.S. Entrevistas individuais: teorias e aplicações. Porto Alegre: FEENG/UFRGS, 2004 - 2007.

RIBEIRO, J.L.D.; NODARI, C. Tratamento de dados qualitativos: técnicas e aplicações. Porto Alegre: FEENG/UFRGS, 2009.

SAPORI, L.F.; SANTOS, R.F.; DER MAAS, L.W. Fatores sociais determinantes da reincidência criminal no Brasil: o caso de Minas Gerais. RBCS, v.32, n.94, 2017.

SINHORETTO, J. et al. Seletividade penal e acesso à justiça. São Paulo: Contexto, 2014.

STAGGS S.M.; LANDREVILLE, K.D. The impact of pretrial publicity on "eye for an eye" retributivist support and malicious perceptions of criminal offenders. Mass Comm. Soc., v.20, n.1, p.116-135, 2017.

STOCKINGS, E.; HALL, W.D.; LYNSKEY M. Prevention, early intervention, harm reduction, and treatment of substance use in young people. Lancet Psychiatr., v.3, n.3, p.280-296, 2016.

STÜRUP, T.; O'MOORE, E.J.; PLUGGE, E. Looking behind the bars: emerging health issues for people in prison. British Med. Bull., p.1-9, 2018.

SUSEPE - Superintendência dos Serviços Penitenciários. Número de presidiários no Estado do Rio grande do Sul, no ano de 2019. Disponível em: <susepe.rs.gov.br>. Acesso em: 29 mar. 2020.

VELOSO, V.B. O jovem em conflito com a lei e o direito à educação básica. In: Reunião CIENTÍFICA REGIONAL DA ANPED SUL. Curitiba, 2016.

VISHER C.A. et al. Evaluating the Long-term effects of prisoner reentry services on recidivism: what types of services matter? Justice Quarterl., v.34, n.1, p.136-165, 2017.

WALTERS, A. Learning for organisations arising from incidents at medway secure. Training Centre. Medway Safeguarding Children Board Serious Case Review, p.35, 2019.

WOOLHOUSE, R.; MCKINLAY, A.; GRACE, C. Women in prison with traumatic brain injury: prevalence, mechanism, and impact on mental health. Int. J. Offender Ther. Comp. Criminol., v.62, n.10, p.3135-3150, 2017. 